\title{
REFLEXÕES SOBRE O ESTÁGIO SUPERVISIONADO NA EDUCAÇÃO DE JOVENS E ADULTOS EM BRAGANÇA (PA)'
}

\author{
Rogerio Andrade Maciel2 \\ Antonio Matheus do Rosário Corrêa ${ }^{3}$ \\ Luane de Cássia Carvalho de Oliveira ${ }^{4}$
}

\section{RESUMO}

Este artigo tem por objetivo refletir sobre a experiência vivenciada, no Estágio Supervisionado na Educação de Jovens e Adultos (ESEJA), Faculdade de Educação, Campus Universitário de Bragança - (PA). Metodologicamente, possui uma abordagem qualitativa, seguido da pesquisa de campo e documental que possibilitaram mapear os documentos norteadores sobre os estágios curriculares no Brasil, utilizou-se ainda, como coleta de dados, a observação participante, elaboração e aplicabilidade de um questionário direcionado para os alunos da $2^{a}$ etapa da Educação de Jovens e Adultos, na Escola Municipal de Educação Infantil e Fundamental Profa. Theodomira Raimunda da Silva Lima, localizada em Bragança-PA. A análise apresentada indica que O ESEJA da Faculdade de Educação, faz parte de um componente curricular obrigatório do Curso de Licenciatura em Pedagogia e possui dois regulamentos: o Projeto Pedagógico do Curso de Licenciatura em Pedagogia (PPC) e o Documento Orientador do Estágio Supervisionado, ambos são fundamentais para o entendimento sobre o papel do pedagogo e da docência, enquanto processos de construção da identidade deste profissional. O texto revela, também, que o ESEJA contribuiu para a resolução das questões emergentes na E.M.E.I.F. Profa. Theodomira Raimunda da Silva, pois

'Este artigo é parte integrante de um relatório de pesquisa produzido durante a Disciplina de Estágio Supervisionado na Educação de Jovens e Adultos - ESEJA, na turma de Pedagogia 2015 pela Universidade Federal do Pará - Campus Universitário de Bragança, no ano de 2017.

2 Doutor em Educação pela Universidade Federal do Pará (UFPA). Professor Assistente da Universidade Federal do Pará, Campus Universitário de Bragança. Membro Integrante do Grupo de Estudo e Pesquisa em Educação de Jovens e Adultos e Diversidade na Amazônia - (GUEAJA/UFPA). ORCID iD: https://orcid.org/0000-0003-1673-5215. E-mail: rogeriom@ufpa.br

3 Acadêmico do Curso de Licenciatura em Pedagogia pela Universidade Federal do Pará (UFPA), Campus Universitário de Bragança, Faculdade de Educação. Bolsista de Apoio à Atividade Acadêmica pela Superintendência de Assistência Estudantil, no Núcleo de Assistência Estudantil do Campus Universitário de Bragança da UFPA. ORCID iD: https://orcid.org/0000-0002-3503-963X.E-mail: matheus.correa112@gmail.com

4 Acadêmica do Curso de Licenciatura em Pedagogia pela Universidade Federal do Pará (UFPA), Campus Universitário de Bragança, Faculdade de Educação. Bolsista-trabalho pela Coordenação de Planejamento, Gestão e Avaliação do Campus Universitário de Bragança da UFPA, no Programa de Pós-Graduação em Linguagens e Saberes da Amazônia (PPLSA). ORCID iD: https://orcid.org/0000-0001-5189-3978. E-mail: Iuane.carvalho5@gmail.com 
possibilitou a elaboração de duas cartilhas "iconográficas e de poesias", como práticas de letramento, a partir das histórias de vida, diversidade cultural e representações dos alunos da $2^{a}$ etapa da EJA, em Bragança-PA.

Palavras-chave: Estágio Supervisionado. Educação de Jovens e Adultos. Práticas de letramento.

\title{
REFLECTIONS ON SUPERVISED PRACTICUM IN YOUNG AND ADULT IN EDUCATION IN BRAGANÇA (PA)
}

\begin{abstract}
This paper brings a reflection on the experience lived in the Supervised Practicum in the Young and Adult Education Program (ESEJA), College of Education, University Campus of Bragança - (PA). Methodologically, it adopts a qualitative approach, followed by a field and documentary research that made it possible to map the guiding documents on practicum as subject in different curricular structures in Brazil. Participant observation and a questionnaire were the methods used for data collection. The questionnaire was administered to students from the 2 nd stage of ESEJA in the municipal school Professora Theodomira Raimunda da Silva Lima, located in Bragança-PA. The analysis presented indicates that the ESEJA from the College of Education is part of a compulsory curricular component of the undergraduate course in Pedagogy and has two regulations: the Pedagogical Project of the undergraduate course in Pedagogy (PPC) and the Supervised Practicum Guidance Document, both are essential for understanding the role of the pedagogue and teaching as processes for the construction of professional identity. The text also reveals that the ESEJA has contributed to the resolution of emerging issues in the school where the study was conducted since it enabled the elaboration of two iconographic and poetry booklets as literacy practices based on life histories, cultural diversity and representations of the students of the second stage of the ESEJA in Bragança-PA.
\end{abstract}

Keywords: Supervised Practicum. Young and adult education. Literacy Practice.

\section{REFLEXIONES SOBRE LA PRÁCTICA SUPERVISADA EN EDUCACIÓN DE JÓVENES Y ADULTOS EN BRAGANÇA (PA)}

\section{RESUMEN}

Este artículo pretende reflexionar sobre la experiencia en las Prácticas Supervisadas en Educación de Jóvenes y Adultos (PSEJA), Facultad de Educación, Campus Universitario de Bragança (PA). Metodológicamente tiene un enfoque cualitativo, seguido por la investigación de campo y documental que permite mapa de los documentos rectores sobre las prácticas en Brasil, no obstante si utiliza, como la recolección de datos, observación participante, preparación y aplicación de un cuestionario dirigido a los alumnos de $2^{a}$ Fase de la Educación de Jóvenes y Adultos en la Escuela Municipal de Educación Infantil y Primaria Profa. Theodomira Raimunda da Silva Lima, situado en Bragança-PA. El análisis indica que lo PSEJA en 
la Facultad de Educación, es parte de un componente curricular necesario. Lo Curso de Grado en Pedagogía y tiente dos reglamentos: el Proyecto Pedagógico del Curso de Grado en Pedagogía (PPC) y documento Guía de las Prácticas Supervisadas, ambos son fundamentales para la comprensión del papel del educador y la enseñanza como procesos de construcción de la identidad de este profesional. El texto revela que el mencionado contribuyó a la resolución de los problemas emergentes en E.M.E.I.P. Profa. Theodomira Raimunda da Silva Lima, porque hizo posible la elaboración de los folletos "I conográfica y la Poesía", como las prácticas de alfabetización, de las historias de vida, representaciones culturales de los estudiantes de la $2^{a}$ Fase de la EJA, en Bragança-PA.

Palabras clave: Prácticas supervisadas. Educación de Jóvenes y Adultos. Prácticas de literacidad.

\section{CONSIDERAÇÕES INICIAIS}

O Estágio Supervisionado na Educação de Jovens e Adultos (ESEJA) caracteriza-se como um elemento da formação inicial que contribui para a ampliação de conhecimentos inerentes a vivências, saberes e aprendizados que são produzidos entre as Instituições de Ensino Superior (IES) e a comunidade escolar.

Para Pimenta e Lima (2006), o Estágio Supervisionado envolve um conhecimento relacionado ao estudo, análise, problematização, reflexão e proposição de soluções, diante das situações decorrentes em instituição escolar. Neste sentido, a análise e reflexões sobre o ambiente escolar fazem parte, continuamente, da prática docente, denominada neste trabalho como regência em classe, antecedida pela observação participante para conhecimento e diagnose das questões-problemas que se encontram nas turmas da Educação de Jovens e Adultos (EJA).

Segundo Almeida e Pimenta (2015), o Estágio Supervisionado não deve ser reduzido meramente a uma atividade prática instrumental, e sim, compreendido como um campo do conhecimento que visa inserção de futuros professores competentes, críticos e reflexivos, permeado por perspectivas de ação para a mudança social, educacional e emancipatória. Assim, faz-se relevante a articulação de uma práxis educativa como forma de produção de conhecimento e de reflexão diante da realidade a ser investigada no contexto escolar. 
Neste artigo, o Estágio Supervisionado na Educação de Jovens e A dultos ocorreu no campo da observação, a partir das vivências em sala de aula e na forma de intervenção, as quais foram levantadas durante a pesquisa na turma da $2^{a}$ etapa da Educação de Jovens e Adultos, as questões emergentes deste cotidiano escolar. $O$ projeto de intervenção sobre práticas de letramento contribuiu tanto para a formação inicial dos alunos estagiários quanto para 0 ensino e aprendizado dos alunos da $2^{a}$ etapa da EJA na E.M.E.I.F. Profa. Theodomira Raimunda da Silva Lima.

Desse modo, o objetivo deste artigo é refletir sobre a experiência vivenciada no Estágio Supervisionado na Educação de Jovens e Adultos (ESEJA), da Faculdade de Educação da Universidade Federal do Pará (UFPA), Campus Universitário de Bragança-PA. O texto está estruturado em quatro seções: uma introdução, que objetivou trazer à tona a concepção geral acerca da temática e seu objetivo; a metodologia, com cunho de abordagem, tipo de pesquisa e seus procedimentos; uma seção sobre marcos legais do ESEJA e o delineamento deste Estágio, desde as reflexões teóricas em sala de aula à consolidação da intervenção sobre práticas de letramento aos alunos da $2^{a}$ etapa da EJA, em Bragança-PA.

\section{CONFIGURAÇÕES METODOLÓGICAS DA PESQUISA}

$O$ estudo se configura numa abordagem qualitativa, em que apresenta os sentidos e significados atribuídos ao Estágio Supervisionado na Educação de Jovens e Adultos desenvolvidos pela Universidade Federal do Pará, Campus Universitário de Bragança-PA. De acordo com Minayo (1994, p. 21-22), a abordagem qualitativa "[...] trabalha com o universo de significados, motivos, aspirações, crenças, valores e atitudes, o que corresponde a um espaço mais profundo das relações, dos processos e fenômenos [...]". Neste âmbito, foi possível sistematizar uma reflexão sobre a concepção do ESEJA e a experiência no cotidiano da Escola Municipal de Educação Infantil e Ensino Fundamental Profa. Theodomira Raimunda da Silva Lima. 
A E.M.E.I.F. Profa. Theodomira Raimunda da Silva Lima fica localizada no município de Bragança, Estado do Pará. A escola oferta os níveis de Educação Infantil (Pré I, II, III), Ensino Fundamental ( $1^{\circ}$ ao $5^{\circ}$ ano), no período diurno, e a modalidade de Educação e Jovens e Adultos $\left(1^{a}\right.$ a $4^{a}$ etapa/Fundamental), no período noturno. O total de alunos matriculados na Educação de Jovens e Adultos era de 95 nas quatro etapas ofertadas. Assim, acompanhou-se a turma da $2^{a}$ etapa da EJA, que continha 28 alunos matriculados e, em média, 18 alunos frequentando regularmente as aulas. $O$ ESEJA aconteceu durante o mês de abril e maio de 2017.

A pesquisa de campo permitiu aproximar àquilo que se "deseja conhecer e produzir conhecimento" (NETO, 1994, p.51), pela qual se identificou a estrutura física da E.M.E.I.F. Profa. Theodomira Raimunda da Silva Lima e a proposição de práticas curriculares que contribuíssem com este universo escolar.

Outro tipo de pesquisa utilizada foi a documental, que implica em coletar informações já existentes, selecionar e analisar o conteúdo encontrado nos dados pesquisados (LAVILLE; DIONNE, 1999). Este tipo de pesquisa permitiu tecer análises nos seguintes documentos: Projeto Político Pedagógico da escola e sua Proposta Pedagógico-Curricular, além das Diretrizes Curriculares Nacionais para a Educação de Jovens e Adultos, Lei $n^{\circ}$ 9.394/1996 (Lei de Diretrizes e Bases da Educação Nacional), a Lei n 11.788, de 25 de setembro de 2008 que versa sobre o estágio curricular do Curso de Pedagogia em nível nacional, e a resolução n 4.399, de 14 de maio de 2013 e $n^{\circ}$ 4.356, de 13 de dezembro de 2012 da UFPA estabelecidas no Curso de Licenciatura em Pedagogia da Faculdade de Educação da UFPA, Campus Universitário de Bragança-PA.

Durante a observação participante identificou-se as reais questõesproblemas da turma de $2^{a}$ etapa da EJA na E.M.E.I.F. Profa. Theodomira Raimunda da Silva Lima. Para Neto (1994), a observação participante se realiza no contato direto entre pesquisador e o fenômeno observado, que buscam construir diretrizes para os profissionais da educação que se encontram em suas ações pedagógicas na escola. 
A observação participante em sala de aula contribuiu para as reflexões de ações pedagógicas sobre os processos de ensino e aprendizagem aos educandos da EJA e com a ação pedagógica do professor. A partir desta observação, elaborou-se, como técnica de coleta de dados, um questionário para identificar o perfil dos estudantes da EJA.

Sendo assim, tanto a observação participante quanto a elaboração do questionário possibilitam identificar o universo das identidades dos alunos nesta turma de $2^{a}$ etapa da EJA. São eles: a) a faixa etária dos estudantes, entre 15 e 52 anos; b) as profissões e/ou ocupações dos alunos - estudante, vendedor/a assalariado/a, vendedor/a autônomo/a, trabalhador/a do lar, servente na construção civil, empregada doméstica; c) em sala de aula, os alunos possuem dificuldades de leitura e escrita, e se sentem cansados à noite, devido exercerem suas profissões no período diurno. Isto só foi possível devido à aplicação de questionários com os estudantes da $2^{a}$ etapa da EJA.

Com base no universo da realidade desta turma da EJA, foi construído o projeto de intervenção e regência em classe. Este projeto foi constituído com base no letramento, mais especificamente, os gêneros textuais, construção iconográfica e socialização de atividades entre os alunos, tendo como principal resultado, a produção de duas cartilhas, contendo poesias e iconografias dos alunos. Neste ínterim, estes momentos permitiram tecer uma prática refletida teoricamente sobre o Estágio Supervisionado na Educação de Jovens e Adultos, na E.M.E.I.F. Profa. Theodomira Raimunda da Silva Lima, em Bragança-PA.

\section{ANÁLISE DOS DADOS: o estágio supervisionado na EJA como encontro de reflexão e produção de conhecimentos}

O Estágio Supervisionado na Educação de Jovens e Adultos contribui de maneira significativa na relação teórico-prática, no campo de formação profissional, ética e didática de discentes-estagiários para atuarem no âmbito escolar. O ESEJA contribui para formação inicial dos alunos porque perpassa pelas vivências acerca da realidade de uma escola, da ação do professor em sala de aula, assim como aproxima o estudante das instituições 
de ensino superior, a identificar o perfil dos alunos da EJA, seus saberes constituídos pelas suas histórias de vidas, e projetar diretrizes para os processos de ensino e aprendizagem no universo da escola.

Considerando este encontro como momento de reflexões, as análises foram tecidas pelos marcos legais que amparam o Estágio Supervisionado na EJA da Universidade Federal do Pará, pela utilização da pesquisa socioantropológica ${ }^{5}$ enquanto campo do conhecimento da realidade escolar, na elaboração do plano de ação e regência em Estágio, que culminou sobre as práticas de letramento e as produções dos alunos desta turma de $2^{a}$ etapa da EJA.

\section{Marcos legais que amparam o Estágio Supervisionado na Educação de Jovens e Adultos, na Faculdade de Educação, Campus Universitário de Bragança-PA}

O Estágio Curricular nos Cursos de Licenciatura em Pedagogia pode ser compreendido como o momento em que o discente, em formação inicial, adentra no contexto escolar para observar, investigar e buscar contribuir na modificação da realidade educacional pesquisada. Para além dessa compreensão, a sua finalidade formativa, estabelecimento de carga horária, níveis de oferta, demanda e organização teórica, prática e legislativa, são delineadas a partir de resoluções promulgadas pelo Conselho Nacional de Educação do Ministério da Educação e os diferentes conselhos das Instituições de Ensino Superior-IES.

Assim, o Conselho Nacional de Educação promulga, no ano de 2006, as Diretrizes Curriculares Nacionais para o Curso de Graduação em Pedagogia, Licenciatura, que contém direcionamentos curriculares, princípios, condições para o ensino e aprendizagem, além do planejamento, procedimentos e avaliação para os órgãos dos sistemas de ensino e IES do

5 De acordo com Freire (2016) a pesquisa socioantropológica efetua a indagação, investigação, constatação e intervenção no contexto cultural dos educandos. Ela possibilita associar a leitura de mundo dos sujeitos com os conteúdos que se pretendem ensinar no cotidiano da escola. Por isto, ensinar, exige pesquisa e respeito pelos saberes dos educandos nas instituições educativas. 
Brasil. Nesse documento, o artigo 8, alínea IV, estabelece que o projeto pedagógico da instituição, ao constituir os estágios curriculares, a efetividade se dará "[...] ao longo do curso, de modo a assegurar aos graduandos experiência profissional, em ambientes escolares e não escolares, que ampliem e fortaleçam atitudes éticas, conhecimentos e competências" (BRASIL, 2006, p. 11) englobando diferentes níveis de ensino e modalidades, como a Educação de Jovens e Adultos.

No que se refere à Lei de Diretrizes e Bases da Educação Nacional de 1996 (LDB 9.394/96), em seu art. 61:

A formação dos profissionais da educação, de modo a atender às especificidades do exercício de suas atividades, bem como aos objetivos das diferentes etapas e modalidades da educação básica, terá como fundamentos: [...] II - a associação entre teorias e práticas, mediante estágios supervisionados e capacitação em serviço (BRASIL, 1996, p. 27.833).

A LDB 9.394/96 traça diretrizes para as instituições de ensino superior propiciarem uma formação inicial em que os estudantes possam atuar em diferentes níveis e modalidades de ensino. Para isto, traz à tona uma interlocução entre teoria e prática, que deve ser vivenciada, durante os estágios supervisionados no contexto escolar.

A Lei $n^{\circ} 11.788$, de 25 de setembro de 2008, é outra diretriz importante para a concepção de estágio no contexto brasileiro. Esta lei apresenta alguns aspectos que orientam os cursos de Licenciatura do ensino superior: a concretização de estágios com caráter obrigatório e não obrigatório, pois cada universidade e suas respectivas faculdades ficam sendo responsáveis por definir um plano específico, que demarque a identidade do estágio em seus cursos de formação; a elaboração do termo de compromisso que perpassa pelo intercruzamento das instituições/empresa; discentes e escolas de educação básica, considerando, ainda, o amparo ao aluno sobre o seguro de acidentes, tanto daquela instituição, que é concedente, quanto da empresa/instituição, deve ter um sujeito responsável por todo o acompanhando do estágio. Estas são algumas diretrizes orientadoras do 
Estagio Supervisionado que tem servido de base para a organização dos projetos dos cursos de Licenciaturas no Brasil.

Na Universidade Federal do Pará (UFPA) existe um regulamento específico, também regido pela lei n. $11.788 / 2008$, em consonância com o Regimento Geral da UFPA, aprovado pelo Conselho Superior Universitário (CONSUN) que, em 14 de dezembro de 2006, define as diretrizes orientadoras para os cursos de licenciaturas da UFPA. E, a partir de 2008, existe o Regulamento de Ensino de Graduação, também aprovado pela CONSUN, que dispõe de quatro artigos que tratam sobre os objetivos, a responsabilidade de organização pelas Faculdades e a definição como atividade curricular obrigatória e não obrigatória do Estágio.

O Conselho Superior de Ensino, Pesquisa e Extensão (CONSEPE) estabelece, em seu artigo 74, que o Estágio Curricular deve:

I - possibilitar a ampliação de conhecimentos teóricos aos discentes em situações reais de trabalho:

II - proporcionar aos discentes o desenvolvimento de habilidades e o aperfeiçoamento técnico-cultural e científico, por intermédio de atividades relacionadas com sua área de formação;

III - desenvolver atividades e comportamentos adequados ao relacionamento sócio profissional (CONSEPE, 2013, p. 55).

Os Estágios, por serem componentes curriculares no campo da formação profissional, permitem aos discentes-estagiários a aplicação, efetividade, avaliação de teorias e reflexão antes aprendidas no curso de graduação, inclusive, no curso de Licenciatura em Pedagogia. Esse momento de ampliação do conhecimento não parte somente do estudante em formação, mas sim, de todos os agentes educativos - docentes responsáveis pelas disciplinas, discentes, comunidade escolar, sociedade envolvidos nos processos educativos construídos no ambiente escolar.

Em 1987, a Universidade Federal do Pará iniciou o processo de interiorização e expansão de seus polos, sendo inaugurado no mesmo ano o Campus Universitário no município de Bragança. Atualmente, o Campus oferta oito cursos na modalidade presencial (Licenciaturas em Pedagogia, História, Letras-Inglês, Letras Português, Matemática, Biologia, Ciências 
Naturais e Bacharelado em Engenharia de Pesca). O curso de Pedagogia foi um dos primeiros cursos implantados no Campus de Bragança, em 1987. Este se apresenta de suma importância para o desenvolvimento científico e educacional da região no campo da formação de professores (CONSEPE, 2013).

Conforme o CONSEPE (2013), no Curso de Licenciatura em Pedagogia da Faculdade de Educação da UFPA - Campus Universitário de Bragança são ofertados cinco estágios obrigatórios: Estágio Supervisionado na Educação de Jovens e Adultos (60 horas); Estágio Supervisionado na Educação Infantil (60 horas); Estágio Supervisionado em Ambientes Não Escolares (60 horas); Estágio Supervisionado no Ensino Fundamental (60 horas); Estágio Supervisionado em Gestão e Coordenação Escolar (75 horas). O ESEJA é um dos componentes curriculares obrigatórios do curso, e tem por finalidade "[...] possibilitar reflexões e análises teórico-práticas e desenvolver uma conduta investigativa nos(as) discentes acerca dos fenômenos educacionais que se manifestam no cotidiano das instituições concedentes do estágio" (CONSEPE, 2013, p. 3).

Os Estágios Supervisionados constituídos no Campus Universitário de Bragança são consolidados por dois documentos orientadores. São eles: o Projeto Pedagógico do Curso de Licenciatura em Pedagogia- (PPC, 2012) e o Documento Orientador do Estágio Supervisionado obrigatório do Curso de Licenciatura em Pedagogia da Faculdade de Educação - Campus Universitário de Bragança, (2013). Esses documentos foram elaborados pelos professores do Campus e da Faculdade de Educação- FACED e são apresentados aos calouros que ingressam nas Licenciaturas, sendo fundamentais para a orientação das disciplinas de estágios.

Tanto o Projeto Pedagógico do Curso de Licenciatura em Pedagogia (PPC) quanto o Documento Orientador do Estágio Supervisionado da Faculdade de Educação - Campus Universitário de Bragança apresentam algumas diretrizes que norteiam o Estágio curricular na Faculdade de Educação. São elas: a) estreit amento entre as instituições de ensino superior e as escolas de educação básica; b) sustentam a base do professor reflexivo 
no âmbito da ação- reflexão-ação, como elemento do estágio curricular; b) fomentam a implementação de projetos de intervenção em ambientes escolares e não escolares, em espaços públicos e privados da região bragantina e em espaços urbanos e do campo, que possam colaborar para os processos de ensino-aprendizagem das escolas e qualificar o aluno das instituições de ensino superior; c) Uma carga horária de 60h da disciplina, sendo organizada em $24 \mathrm{~h}$ deste total, para carga horária teórica e reflexiva em sala de aula, com cunho de orientações para os estudantes e no campo de estágio, e 36h para carga horária de pesquisa, observação, levantamento de questões emergentes do cotidiano da escola, elaboração de projetos de intervenção e regência. Além disso, na carga horária da disciplina de Estagio Supervisionado em Gestão e Coordenação Escolar, existe uma diferenciação que perpassa por 30h de orientação reflexiva e 45h com a vivência de campo destes dois atores sociais, totalizando a carga horária de 75 horas.

Esse movimento entre as leis nacionais orientadoras de Estágio (lei n. 11.788/2008, LDB 9.394/96) é fundamental para a organização dos Cursos de Licenciaturas da Universidade Federal do Pará, que desde 2006 vem organizando pelo CONSUN os Estágios supervisionados nos Campi do interior do Estado do Pará. Assim, o Estágio Supervisionado da Faculdade de Educação é um componente curricular obrigatório do Curso de Licenciatura em Pedagogia, e está articulado com os marcos legais fundantes para a organização do Estágio, que permitem ao estudante compreender o papel do pedagogo e da docência enquanto processos de construção da identidade deste profissional.

\section{Estágio Supervisionado na Educação de Jovens e Adultos: interlocução com a pesquisa socioantropológica, plano de ação e regência}

A interlocução da pesquisa com a regência no ESEJA está articulada à própria organização da disciplina, que foi materializada da seguinte maneira: uma carga horária de 24 horas discutidas a partir de textos de Pimenta e Lima (2006), Fontes e Lima (2010) e Soares (2006). Estes autores 
subsidiam a concepção de Estágio Curricular no Curso de Licenciatura em Pedagogia. No segundo momento foram apresentados, a partir do Projeto Pedagógico do Curso de Licenciatura em Pedagogia (PPC) e do Documento Orientador do Estágio Supervisionado da Faculdade de Educação, os documentos que orientam o ESEJA para os alunos, tendo como base dois professores, sendo um titular da disciplina. Os documentos orientadores são: termo de compromisso da instituição concedente e da universidade; fichas de frequência do Estágio contendo atividades, carga horária e assinaturas; diário de campo, que possui descrições das atividades na escola e os aspectos reflexivos dos alunos, isto dará base para a construção de relatórios; proposição de um modelo de plano de ação; projeto de intervenção e relatório para os alunos organizarem todos estes documentos, escanearem e gravarem em CD-ROM; e, por fim, o acompanhamento dos professores, por equipes de alunos, nas instituições escolares. Vale mencionar ainda que, no momento da disciplina do ESEJA, foram constituídas seis equipes de trabalho para investigar e intervir nas escolas da região bragantina. Dentre essas equipes, o referido estudo faz parte da experiência vivenciada por uma equipe de trabalho.

Após a orientação reflexiva em sala de aula, operacionalizou-se às 36 horas de vivência do aluno nos espaços escolares, que se inicia com a realização da pesquisa socioantropológica. Para Freire (2016), o ato de pesquisa se faz importante para constatar e intervir na realidade, educando não somente aos alunos como a si próprios, na efetividade da prática de ensino.

$\mathrm{Na}$ pesquisa e observação, identificou-se na E.M.E.I.F. Profa. Theodomira Raimunda da Silva Lima os seguintes aspectos: o uso social dos espaços físicos da escola pelos sujeitos; organização didática e pedagógica da aula; conhecimentos trabalhados por professores e alunos; recursos, métodos e avaliação da aprendizagem; organização do trabalho pedagógico, do espaço e tempo; relações sociais e educacionais entre professor/aluno e aluno/aluno. 
As aulas eram organizadas em conversa inicial do professor com os alunos, seguida de breve apresentação do assunto que seria abordado, com diagnóstico do conhecimento preliminar dos alunos e, consequente, explicação dos conteúdos, ditado dos conteúdos prescritos no livro didático ou transcrição do que era escrito no quadro pelo professor; exercício de avaliação de conteúdo, por meio de questionamentos orais aos alunos.

Dentre as problemáticas encontradas em sala de aula, através do período destinado à observação, foram traçadas atividades relacionadas às questões de leitura, escrita e desenho, tendo como eixo o letramento dos estudantes, de modo que contribuísse no aprendizado e efetividade de sua participação na ação de ensino.

Dessa maneira, constataram-se as questões-problema na realidade observada, o que subsidiou a elaboração de um plano de ação intitulado 'Práticas de letramento na EJA: diálogos com gêneros textuais e iconográficos (poesia e imagem). Com isso, a proposta de plano de ação para a turma de $2^{a}$ etapa da EJA está relacionada à integração entre a historicidade dos sujeitos e a produção de textos e imagens como produção de conhecimento para desenvolver a percepção, criatividade e habilidades de leitura e escrita, não somente de codificações, mas de interpretação da realidade por meio de práticas de letramento.

Desse modo, se faz necessário planejar uma trajetória para realização e encadeamento das atividades. O planejamento na Educação de Jovens e Adultos, nesse sentido, significa "comprometer-se com o que foi considerado importante para solução de questões apresentadas pela situação e espaço onde o trabalho educativo acontece" (BRASIL, 2006, p. 47).

No planejamento do "Plano de Ação" constituíram-se dois aspectos: a) a identificação sobre as dificuldades de leitura e escrita que se constituiu enquanto um processo formativo, funcionalidade e finalidade de formação de sujeitos críticos, reflexivos e produtores de conhecimentos; b) o reconhecimento das dificuldades dos alunos, relacionadas à escrita de palavras simples, desconhecimento de consoantes, vogais e formações 
silábicas, organização de frases e ideias e recusa de alunos em efetuarem algumas atividades propostas em sala de aula.

A partir da percepção destas adversidades identificadas na $2^{a}$ etapa da EJA, desenvolveu-se o plano de ação, como forma de contribuir no aprendizado dos alunos na perspectiva do letramento. Diante das dificuldades dos educandos, entende-se que as formas de aprendizagem diferenciadas são fundamentais para $\circ$ respeito e valorização da diversidade cultural dos alunos, considerando as relações sociais do aluno na Educação de Jovens e Adultos (DURANTE, 1998). Então, o objetivo geral do plano foi propiciar o letramento dos sujeitos da EJA através da leitura, construção de poesias e criação de iconografias, levando em consideração suas historicidades e culturas relacionadas a momentos marcantes, na vida dos estudantes desta modalidade da Educação Básica.

Os objetivos específicos do plano de ação foram configurados pela seguinte práxis educativa: a) Apresentar estratégias de aprendizagem por meio das práticas de letramento aos alunos da EJA; b) Demonstrar que os sujeitos da EJA são produtores de conhecimento e que estes conhecimentos considerados populares, podem se relacionar com o conhecimento escolar; c) Construir cartilhas de poesias e imagens, a partir das histórias de vida dos alunos da EJA.

Soares (1998) nos diz que o letramento, constituído pelo termo literacy, diz respeito à pessoa que assume um estado ou condição de quem aprendeu a ler e escrever e, consequentemente, interfere nos fatores sociais, culturais, políticos, econômicos, cognitivos e linguísticos, seja para um grupo inserido ou para o indivíduo que adquiriu tais habilidades e as usa de forma corrente.

Neste cont exto, Freire (2009, p. 20) afirma que:

[...] a que a leitura do mundo precede sempre a leitura da palavra e a leitura desta implica a continuidade da leitura daquele. Na proposta que me referi acima, este movimento do mundo a palavra e da palavra para ao mundo está sempre presente. Movimento que a palavra dita flui no mundo mesmo através da leitura que dele fazemos. De alguma maneira, porém, podemos ir mais longe e dizer que a leitura da palavra não é apenas precedida pela leitura do 
mundo mas por uma certa forma de "escreve-lo" ou de "reescrevelo", que dizer, de transformá-lo através de nossa prática consciente.

Neste sentido, a produção do conhecimento a ser usado em sala de aula foi o gênero poesia, no que cerne suas variadas formas, assim como o conceito do que é a poesia, a estrutura que está definida e os contextos em que podemos encontrá-las, a exemplo da música e literatura brasileiras, dos movimentos sociais, dentre outros. Deste modo, se propôs a construir com os alunos a compreensão sobre esse gênero literário, interligando-se a prática do letramento.

De acordo com Martine (1994), a leitura e a produção de imagens é uma representação visual, e nela contém uma leitura visual de um objeto, sentimento, ideia ou pensamento, através de técnicas de fotografia, de pintura, de desenho, de vídeo. Essa produção do conhecimento abordou o estudo sobre os diferentes tipos de iconografias, e como isto está presente em diferentes contextos, sobre o cotidiano dos alunos da EJA.

A utilização dos tipos de gêneros e imagens, interligadas às práticas de letramento para e com os alunos, se deu pela leitura de mundo que os alunos da EJA têm com suas histórias de vida, que formam as representações e podem ser transmitidas através da imagem, com as características e particularidades existentes, explorando as qualidades e dificuldades que cada estudante revela. Deste modo, caracterizou-se as atividades acerca das iconografias em semióticas, considerando "o seu modo de produção de sentido; por outras palavras, a maneira como eles suscitam significados, ou seja, interpretações" (MARTINE, 1994, p. 30).

Essas combinações podem ser utilizadas em seus cotidianos, não somente como conteúdos relacionados à comunicação e socialização para com seus pares, mas sim, na amplitude que a poesia e as imagens oferecem aos indivíduos pertencentes a determinados grupos sociais. O conhecimento gestado neste processo desencadeia uma série de benefícios e habilidades que são desenvolvidas pelos próprios estudantes e que podem ser utilizadas 
nos processos de escolarização. No desenho curricular, a produção do conhecimento const it uiu-se do seguinte modo:

QUADRO 1 - Produção do conhecimento para o desenho curricular da EJA na escola

\begin{tabular}{|c|c|c|c|}
\hline DISCIPLINA & CONTEÚDO & $\begin{array}{l}\text { MODALIDADE/NÍVEL } \\
\text { DE ENSINO }\end{array}$ & OBJETIVOS \\
\hline $\begin{array}{l}\text { Língua } \\
\text { Portuguesa, } \\
\text { Artes, } \\
\text { Matemática, } \\
\text { História e } \\
\text { Geografia. }\end{array}$ & Poesia. & $\begin{array}{c}2^{a} \text { Etapa da } \\
\text { EJA/Fundamental }\end{array}$ & $\begin{array}{l}\text { a) Desenvolver habilidades } \\
\text { referentes ao letramento; } \\
\text { b) Exercitar a leitura, escrita e } \\
\text { interpretação textual; } \\
\text { c) Produzir textos a partir da } \\
\text { historicidade dos sujeitos; }\end{array}$ \\
\hline $\begin{array}{c}\text { Língua } \\
\text { Portuguesa, } \\
\text { Artes, História e } \\
\text { Geografia. }\end{array}$ & $\begin{array}{l}\text { Iconografia } \\
\text { (imagem) }\end{array}$ & $\begin{array}{c}2^{a} \text { Etapa da } \\
\text { EJA/Fundamental }\end{array}$ & $\begin{array}{l}\text { a) Apresentar a importância, a } \\
\text { necessidade e contribuições que } \\
\text { as imagens trazem para nossas } \\
\text { vidas; } \\
\text { b) Desenvolver competências no } \\
\text { que diz respeito a leitura de } \\
\text { mundo e das imagens do } \\
\text { cotidiano em uma perspectiva } \\
\text { crítico-reflexiva; } \\
\text { c) Produzir imagens, a partir de } \\
\text { representações existentes nas } \\
\text { subjetividades dos sujeitos, a fim } \\
\text { de propiciar leitura e } \\
\text { interpretação destas em grupo. }\end{array}$ \\
\hline
\end{tabular}

Fonte: elaborado pelos autores, 2017.

Durante o plano de ação para regência em sala de aula, buscou-se integrar as disciplinas com o intuito de relacionar os conhecimentos dos alunos com o conhecimento escolar. As imagens e poesias, como produção artística, linguística e histórico-geográfica, remontam à realidade dos estudantes, tanto pelos espaços que integram quanto pelos sentimentos, expectativas e culturas que são criados a partir de suas vidas. Segundo Freire (2009), a construção do conhecimento escolar deve dialogar com o universo do vocabulário dos sujeitos jovens e adultos, pois isso facilita ao professor uma maior compreensão do próprio processo pedagógico, que é constituído em meio à seleção e organização dos conhecimentos imersos por uma orientação cultural ao currículo. 
A aplicação do plano de intervenção delineou-se em alguns momentos. No primeiro, apresentou-se uma introdução aos estudos de poesias, através de diagnóstico do conhecimento de mundo dos educandos, a conceituação de poesia, sua estruturação, importância e tipos de textos poéticos; e, ao final da aula, foi solicitado aos alunos que produzissem poesias baseadas em suas histórias, saberes e vivências. No segundo momento ocorreu a socialização das produções por meio de leitura coletiva e comentários sobre as poesias, a exemplo:

\section{Filhos Queridos}

Durante muito tempo fui sozinho, Mas Deus colocou alguém no meu caminho

E agora já não sigo mais sozinho Pois tenho uma mulher e cinco filhos.

Hoje sou feliz com minha família

Com meus filhos já crescidos, A cada passo deles, mais orgulho eu sinto. Obrigado Deus, por meus filhos queridos.

(Elaborado pelo aluno J. R., 2017).

\section{Meu Marido}

Meu marido, meu amado marido, Sou tão feliz contigo. Tu és meu abrigo, Meu amor verdadeiro.

Tu és meu companheiro, Meu amigo e parceiro. Sou tão feliz contigo E com a nossa família.

(Elaborado pela aluna A. M. S. R., 2017).

Em "Filhos queridos" e "Meu marido" são apresentados os saberes e vivências dos laços familiares dos alunos, traços estes que devem ser valorizados e vistos como princípio didático dentro da prática docente, ou seja, as suas vivências se tornam fundamentos do processo educativo, pois as produções do conhecimento contidas nestas poesias estão permeadas pelos tipos de família, valores humanos, religiosidade e trajetórias de vida. 


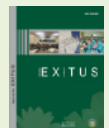

Estas são as marcas impressas na leitura da palavra que antecede a leitura de mundo e serve de base para as práticas de letramento no âmbito escolar.

De acordo com Silva e Araújo (2012, p. 3), as práticas de letramento em perspectiva crítica apresentam, em um dos seus elementos, a "[...] relevância de se analisar a história de vida do sujeito, o qual é visto como um ator ativo e versátil que, dependendo da situação, recorre a diferentes práticas letradas com as quais mantém contato". Em outras poesias, são retratadas outras histórias, a exemplo:

Saudades de meu pai

Que saudades de meu pai, Que há muito tempo não vejo Que me deu tanto amor e carinho E que hoje não posso tê-lo.

Que saudades de meu pai Que afastaram de mim Espero vê-lo em breve Para que eu volte a sorrir.

(Elaborado pela aluna R. S., 2017).

Bragança é meu lar

Nasci no Maranhão E cresci no Amapá, Hoje vivo em Bragança Que agora é meu lar.

Viajo com frequência Pois tenho que trabalhar, Mas tenho sempre muita pressa Para casa voltar.

(Elaborado pela aluna T. S., 2017).

Nestas poesias, os saberes e vivências estão articulados à produção do conhecimento, do sentimento de saudade, dos seus lugares de origem, da relação entre Estados e municípios. Assim, faz-se relevante considerar as vivências em conjunto com as memórias dentro do processo de letramento, pelo teor representacional e relevante que as histórias presentes nas poesias 
revelam, como, por exemplo, viagens marcantes e a vida diária representada pelo trabalho ou pelo cuidar do companheiro e filhos. Considerando isso, Oliveira, Lima e Pinto (2012, p. 191) afirmam que "os alunos atendidos pela EJA formam um grupo muito diversificado, que venceu barreiras para estar de volta à escola e que luta diariamente contra o cansaço e outros obstáculos de sua vida cotidiana para estar na sala de aula".

Em outro momento de regência, realizou-se a sondagem de conhecimentos dos alunos em relação a imagens, seguido de breve introdução aos estudos de imagens. Através de diagnóstico das histórias de vida dos educandos, apresentou-se a conceituação, tipos de imagens e suas estruturações. Ao final foi solicitado que produzissem uma imagem com base em suas histórias de vida e vivências do cotidiano.

Figura 1 - Expressão de família e memórias da infância

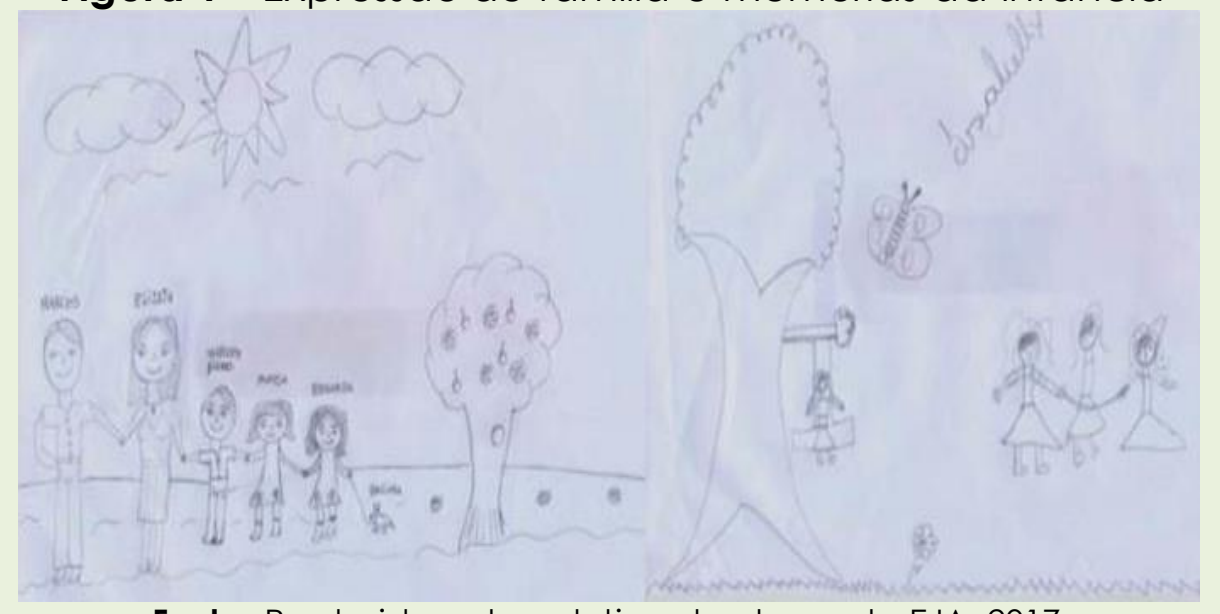

Fonte: Produzido pelo coletivo de alunos da EJA, 2017.

De acordo com Freire $(2009, \mathrm{p}, 20)$ "[...] a leitura do mundo precede sempre à leitura da palavra, e a leitura desta implica a continuidade da leitura daquele". Assim, os sentidos e significados atribuídos às imagens apresentam diversidades sociais e culturais, por meio das experiências que constituem a vida dos sujeitos, e que carecem da valorização na prática docente. Logo, as imagens acima apresentam a leitura de mundo dos alunos, imersa em suas histórias de vida, de uma diversidade cultural em comunidades do município de Bragança-PA. 
Em outra imagem apresenta-se a seguinte representação:

Figura 2 - Guardanapo representando vivências em região campesina

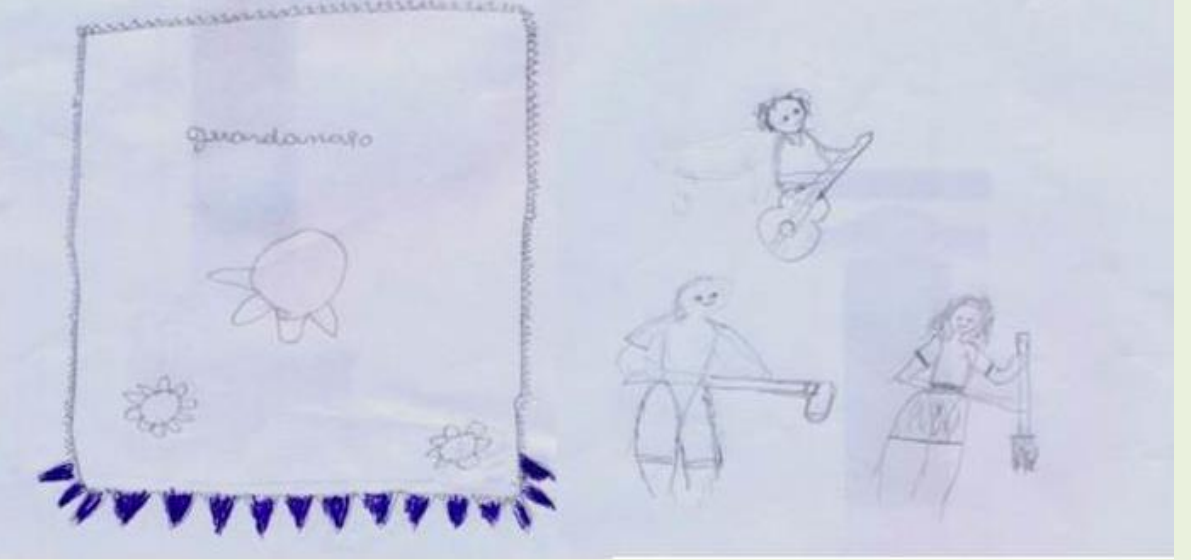

Fonte: Produzido pelo coletivo de alunos da EJA, 2017.

Nestas imagens, a primeira remete ao trabalho doméstico e sua importância na vida do sujeito, ao qual tem muito carinho; a segunda, às boas lembranças que o aluno viveu no campo e às contribuições para a história de vida dele, principalmente relacionadas à musicalidade. Faz-se relevante considerar as vivências em conjunto com as memórias dentro do processo cultural, pelo teor representacional e relevante que as histórias nos revelam como, por exemplo, viagens marcantes e a vida diária representada pelo trabalho, pelo cuidar do companheiro e filhos ou pelo sonho da casa própria.

Durante as vivências e experiências do Estágio Supervisionado na EJA foi possivel compreender as histórias e vivências dos alunos, possibilitando criar práticas que valorizem a diversidade cultural dos alunos. Neste sentido, as atividades realizadas em sala de aula, durante o período de regência, contribuíram de forma significativa para a formação inicial dos alunos do Curso de Licenciatura em Pedagogia. As participações na atividade de construção de poesias e imagens pelas quais os alunos representaram suas histórias de vida, a partir das experiências de vida destes sujeitos, consolidaram-se em processos de representações, tornando os alunos protagonistas desse processo educativo no cotidiano escolar. 
Assim, tanto a produção das poesias quanto as iconografias produzidas pelo coletivo de sujeitos da Educação de Jovens e Adultos, culminou em duas cartilhas, sendo a primeira intitulada "Histórias, Saberes e Vivências na Educação de Jovens e Adultos: Uma Ontologia Poética", que contém as poesias escritas dos alunos da Educação de Jovens e adultos. Na perspectiva de Freire (1987), a ontologia faz referência à existência do ser humano enquanto sujeito humanizado, produtor de conhecimento a partir de suas vivências, objetivando transformar a sociedade em que vive.

Figura 3: Produção da cartilha sobre poesias dos alunos da EJA

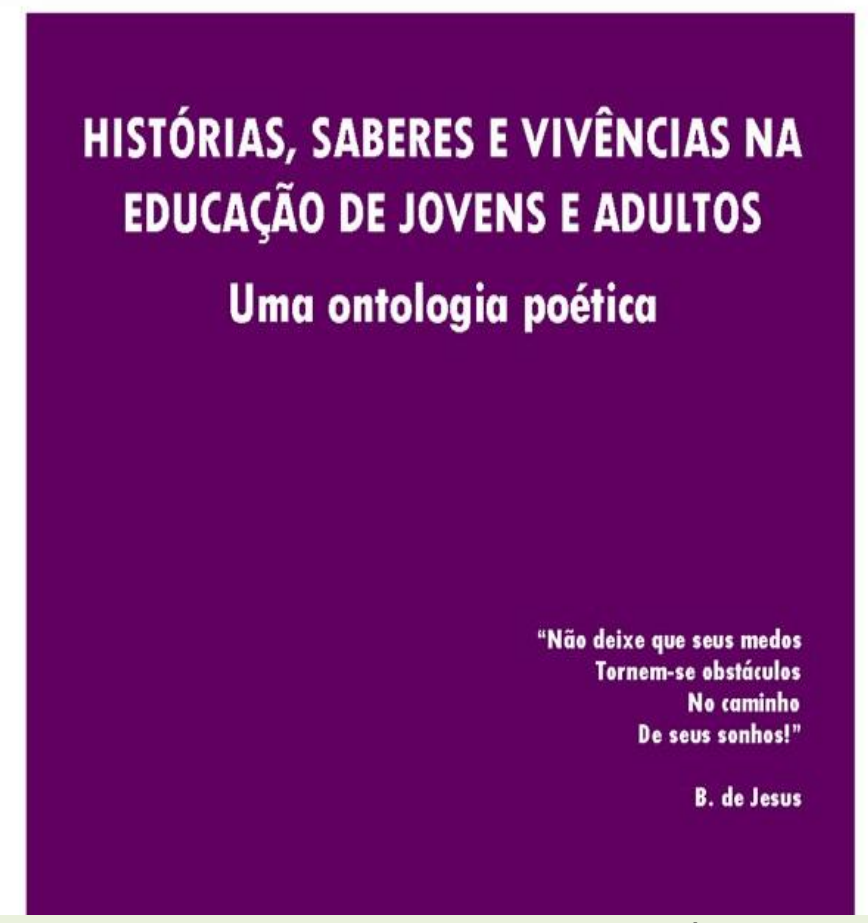

Fonte: Elaborado pelos discentes-estagiários, 2017.

$\mathrm{Na}$ cartilha "Histórias, Saberes e Vivências na Educação de Jovens e Adultos: Uma Ontologia Poética" estão imersos os relatos dos alunos pelo uso de poesias para o ensino e aprendizado que não se esgotou no saber fazer pedagógico em sala de aula, mas partiu das histórias de vida e identidades dos alunos da EJA, possibilitando criar práticas que valorizem a diversidade e a leitura de mundo dos sujeitos. Freire (2016) nos diz que as práticas de letramento para os alunos da EJA, devem partir de suas experiências de 
vida, de sua oralidade, pelo diálogo entre professor e alunos, como base de produção de conhecimentos na ação pedagógica docente.

Na segunda cartilha, denominada "Representações Iconográficas na Educação de Jovens e Adultos: Histórias e Contextos", se apresentam as imagens construídas pelos alunos da EJA. Para Martine (1994), as representações construídas a partir das imagens remetem a uma comunicação visual, artística e sociocultural dos alunos que passam a ser produtores de seus próprios conhecimentos. Após formatação e edição dos textos e das imagens, foram apresentadas as cartilhas aos alunos e professores da sala da EJA como forma de contribuir com a docência sobre as práticas de letramento neste universo escolar.

Figura 4: Produção da cartilha sobre iconografias dos alunos da EJA

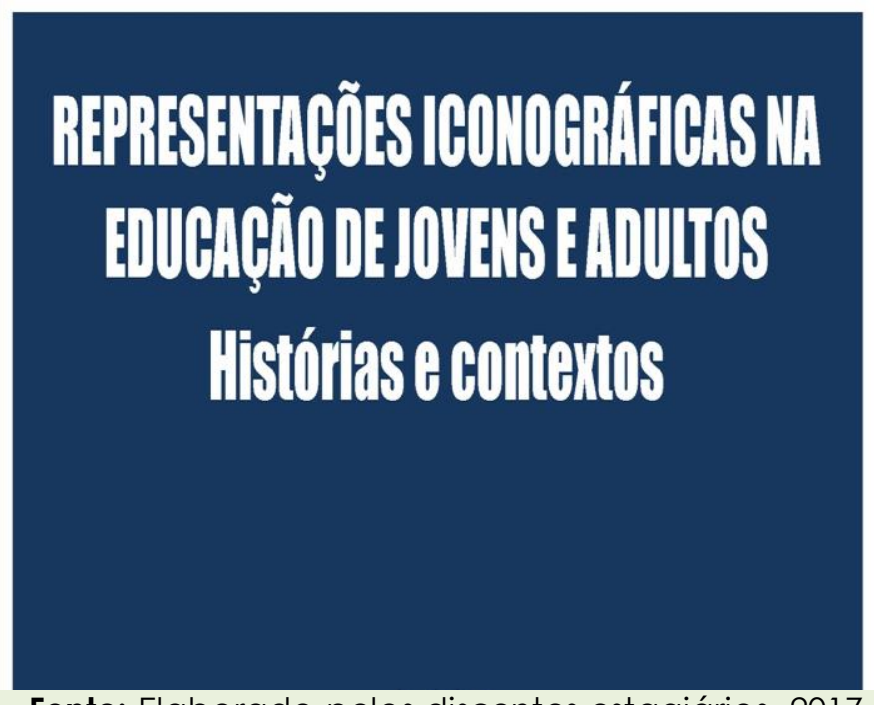

Fonte: Elaborado pelos discentes-estagiários, 2017.

Nesta segunda cartilha, "Representações Iconográficas na Educação de Jovens e Adultos: Histórias e Contextos" as produções dos alunos permitiram tecer a valorização das histórias de vida dos sujeitos da Educação de Jovens e Adultos. Nesse sentido, as iconografias produzidas pelo coletivo de estudantes da EJA apresentam um encontro de relações sociais, culturais, familiares, de trabalho e, principalmente, da infância, manifestadas pelos seus saberes e vivências em suas histórias de vida que foram balizadores para o aprendizado escolar. 
As produções iconográficas e de poesias presentes nestas duas cartilhas, gestadas pelos alunos-estagiários e materializados com os alunos da $2^{a}$ etapa da Educação de Jovens e Adultos, propiciaram uma prática de letramento que contribuiu para o processo de ensino e aprendizagem dos alunos da EJA, uma vez que eles participaram da ação de ensino e da produção do conhecimento de forma coletiva. Por fim, após a vivência com este estágio, ocorreu a socialização das diversas experiências vivenciadas pelos alunos do estágio em sala de aula, no Campus Universitário de Bragança, com momentos de tessituras de saberes e afirmação de identidades dos futuros profissionais da educação para atuarem nos ambientes escolares.

Dessa forma, as reflexões acerca do ESEJA possibilitou problematizar a realidade da turma de $2^{a}$ etapa da EJA, na E.M.E.I.F. Profa. Theodomira Raimunda da Silva Lima, como perspectiva de criação de estratégias de aprendizagens e ensino, que geraram as produções de poesias e iconografias no contexto desta realidade. Portanto, o ESEJA constituído no Curso de Licenciatura da Universidade Federal do Pará, Campus Universitário de Bragança, se propôs, na formação inicial de futuros professores: produzir, conhecer, criar novas ações e diferentes reflexões, no sentido de construir as identidades dos profissionais da educação a partir das experiências vivenciadas com o Estágio Supervisionado na Educação de Jovens e A dultos no Curso de Licenciatura em Pedagogia, em Bragança-PA.

\section{CONSIDERAÇÕES FINAIS}

O Estágio na Educação de Jovens e adultos, além de contribuir para a formação inicial nos cursos de licenciatura, torna-se imprescindível e indissociável, no que diz respeito à troca de conhecimentos e vivências, aproximando o aluno-estagiário da realidade dos alunos e promovendo o conhecimento de suas histórias e da diversidade cultural existente na sala de aula.

Deste modo, o contexto escolar pode ser visto como uma instituição formadora, constituída de sujeitos que advém de outros lugares, cheios de 
saberes, sentimentos e expect ativas em relação à escola, tendenciado a ser um retrato da realidade dos alunos que a circundam.

Um dos pontos principais da experiência proporcionada em sala de aula, mediado pelo ESEJA, é identificar a realidade do aluno, o modo como ele se desenvolve e as suas limitações, além de saber utilizar suas próprias experiências de vida como proposição de ensino e aprendizagem. Neste estudo, a proposta de ontologia poética relacionada à prática de letramento e à construção de imagens pelos alunos, por meio da iconografia, possibilitou o desenvolvimento da criticidade e reflexão sobre suas histórias de vida.

Neste âmbito, considera-se que esta experiência desenvolvida durante o ESEJA permitiu refletir sobre as seguintes afirmativas: a) o desenvolvimento do estágio é importante para a produção do conhecimento, tanto para as instituições de ensino superior quanto para as escolas de Educação Básica; b) a diversidade cultural e as histórias de vida dos alunos são a base para a proposição de práticas de letramento no contexto escolar; c) a compreensão sobre o significado das poesias e das imagens, criadas a partir do cotidiano dos alunos, tornam os sujeitos da EJA protagonistas dos processos de aprendizagem e ensino; d) com esta modalidade da Educação Básica, o ESEJA contribui (u) para o envolvimento e identificação dos discentes-estagiários, enquanto futuros profissionais da educação no Estado do Pará.

\section{REFERÊNCIAS}

ALMEIDA, M.I.; PIMENTA, S. G. A presentação. In. ALMEIDA, M. I.; PIMENTA, S. G. Estágios supervisionados na formação docente. São Paulo: Cortez, 2015. p. 9-14.

BRASIL. Lei no 9.394, de 20 de Dezembro de 1996. Lei de Diretrizes e Bases da Educação Nacional. Diário Oficial da República Federativa do Brasil. Brasília, DF, 24 dez. 1996. Seção 1, p. 27833.

BRASIL. Lei n $n^{\circ} 11.788$, de 25 de setembro de 2008. Diário Oficial da República Federativa do Brasil. Brasilia, DF, 26 set. 2008. Seção 3, (publicação original). Disponível em: 
http://www.cvm.gov.br/export/sites/cvm/menu/acesso_informacao/servidor es/estagios/3- LEGISLACAO-DE-ESTAGIO.pdf

BRASIL. Resolução CNE/CEB $\mathbf{n}^{\circ}$ 1, de 5 de julho de 2000. Estabelece as Diretrizes Curriculares Nacionais para a Educação de Jovens e Adultos. Disponível em: <http://portal.mec.gov.br/cne/arquivos/pdf/CEBO12000.pdf> Acesso em: 20/02/2018.

BRASIL. Resolução CNE/CP n 1, de 15 de maio de 2006. Institui Diretrizes Curriculares Nacionais para o Curso de Graduação em Pedagogia, licenciatura. Diário Oficial da República Federativa do Brasil, Poder Executivo, Brasília, DF, 16 mai. 2006. Seção 1, p. 11.

BRASIL. Trabalhando com a educação de jovens e adultos: avaliação e planejamento. Brasilia: MEC; SECAD, 2006.

CONSELHO SUPERIOR DE ENSINO, PESQUISA E EXTENSÃO (CONSEPE).

Resolução n. 4.399, de 14 de maio de 2013. Aprova o Regulamento do Ensino de Graduação da Universidade Federal do Pará. Belém, PA: EDUFPA, 2013.

CONSELHO SUPERIOR DE ENSINO, PESQUISA E EXTENSÃO (CONSEPE).

Resolução n. 4.356, de 13 de dezembro de 2012, Aprova o Projeto Pedagógico do Curso de Licenciatura em Pedagogia, de interesse do Campus Universitário de Bragança. Belém, PA, 2012.

DURANTE, M. Alfabetização e Alunos: leitura e produção de texto. Porto Alegre: Grupo, 1998.

FACULDADE DE EDUCAÇÃO. Documento Orientador do Estágio Supervisionado obrigatório do curso de Pedagogia da Faculdade de Educação. Campus Universitário de Bragança/UFPA, 2013.

FA CULDADE DE EDUCAÇÃO. Projeto Pedagógico do Curso de Pedagogia. Campus Universitário de Bragança/UFPA, 2012. Disponível em: $<$ www.faced.ufpa.br/index.php/documentos/123-versao-2012> Acesso em: 22/02/2018.

FREIRE, P. A importância do ato de ler: em três artigos que se completam. 50. ed. São Paulo, Cortez, 2009.

FREIRE, P. Pedagogia da autonomia: saberes necessários à prática educativa. 34. ed. Rio de Janeiro: Paz e Terra, 2016.

FONTES, J. A. S.; LIMA, D. M. O papel do coordenador pedagógico junto ao corpo docente na educação de jovens e adultos da rede municipal. In. ENCONTRO DE PESQUISA EM EDUCA ÇÃO DE ALA GOAS, V., 2010, Alagoas. Anais do V EPEL - Pesquisa em Educação: desenvolvimento, ética e 
responsabilidade social. Alagoas: Universidade Federal de Alagoas, 2010, p. 1-15. Disponível em: <http://dmd2.webfactional.com/media/anais/O-PAPELDO-COORDENADOR-PEDA GOGICO-JUNTO-AO-CORPO-DOCENTE-NA-REDEEDUCACAO-DE-JOVENS-E-ADULTOS-DA-REDE-.pdf>

LA VILLE, C.; DIONNE, J. A construção do saber: manual de metodologia da pesquisa em ciências humanas. Tradução de Heloísa Monteiro e Francisco Settineri. Porto Alegre: Artmed; Belo Horizonte: Editora UFMG, 1999.

MARTINE, J. Introdução à análise da imagem. Tradução: José Eduardo Rodil. Lisboa: Editora 70, 1994.

MINAYO, M. C. S. Ciência, técnica e arte: o desafio da pesquisa social. In. MINAYO, M. C. S. (Org.). Pesquisa social: teoria, método e criatividade. Petrópolis, RJ: Vozes, 1994. p. 9-29.

NETO, O. C. O trabalho de campo como descoberta e criação. In. MINAYO, M. C.S. (Org.). Pesquisa social: teoria, método e criatividade. Petrópolis, RJ: Vozes, 1994. p. 51-66.

OLIVEIRA, A.B. T.; LIMA, M. B.; PINTO, E. A. T. Educação de jovens e adultos (EJA): perspectivas metodológicas e aprendizagem significativa. Mimesis, $v$. 33, n. 2, p. 181-204, 2012.

PIMENTA, S. G.; LIMA, M. S. L. Estágio e docência: diferentes concepções.

Revista Poiesis, vol. 3, n. 3 e 4, p. 5-24, 2006. Disponível em:

<http://www.revistas.ufg.br/polesis/article/view/10542>

SILVA, E. M.; ARAÚJO, D. L. Letramento: um fenômeno plural. Revista Brasileira de Linguística Aplicada, v.1 n. 08, p.1-18, 2012.

SOARES, L. O educador de jovens e adultos em formação. In. REUNIÃO ANUALDA ASSOCIAÇÃO NA CIONAL DE PÓS-GRADUAÃO E PESQUISA EM EDUCA ÇÃO $, 29,2006$, Caxambu. Anais da 29 Reunião Anual da ANPEd. Caxambu: Universidade Federal de Minas Gerais, 2006. p. 1-20. Disponível em: http://29reuniao.anped.org.br/trabalhos/trabalho/GT18-2030--Int.pdf

SOARES, M. Letramento: Um tema em três gêneros. Belo Horizonte: Autêntica, 1998.

Recebido em: 22 de maio de 2018.

Aprovado em: 15 de fevereiro de 2019. 